\title{
Identification and validation of a novel microRNA-like molecule derived from a cytoplasmic RNA virus antigenome by bioinformatics and experimental approaches
}

\author{
Jiandong Shi ${ }^{1}$, Zhiqing Duan ${ }^{1}$, Jing Sun ${ }^{1}$, Meini Wu${ }^{1}$, Bin Wang ${ }^{2}$, Jing Zhang ${ }^{1}$, Haixuan Wang ${ }^{1}$, Ningzhu Hu ${ }^{1}$ \\ and Yunzhang $\mathrm{Hu}^{1 *}$
}

\begin{abstract}
Background: It is generally believed that RNA virus replicating in the cell cytoplasm would not encode microRNAs (miRNAs) due to nucleus inaccessibility. Recent studies have described cytoplasmic RNA virus genome-derived miRNAs in West Nile virus (WNV) and Dengue virus (DENV). However, naturally occurring miRNAs derived from the antigenome of a cytoplasmic RNA virus have not been described.

Methods: Hepatitis A virus (HAV) was served as a model virus to investigate whether the antigenome of a cytoplasmic RNA virus would be processed into miRNAs or miRNA-like small RNAs upon infection. HAV antigenome was queried for putative miRNA precursors (pre-miRNA) with the VMir analyzer program. Mature miRNA prediction was performed using MatureBayes and Bayes-SVM-MiRNA web server v1.0. Finally, multiple experimental approaches, including cloning and sequencing-, RNAi-, plasmid-based miRNA expression- and luciferase reporter assays, were performed to identify and validate naturally occurring viral antigenome-derived miRNAs.

Results: Using human HAV genotype IA (isolate $\mathrm{H} 2)(\mathrm{HAVH} 2)$, a virally encoded miRNA-like small RNA was detected on the antigenome and named hav-miR-N1-3p. Transcription of viral pre-miRNA in KMB17 and HEK293T cells led to mature hav-miR-N1-3p production. In addition, silencing of the miRNA-processing enzyme Dicer or Drosha caused a dramatic reduction in miRNA levels. Furthermore, artificial target of hav-miR-N1-3p was silenced by synthesized viral miRNA mimics and the HAVH2 naturally-derived hav-miR-N1-3p.
\end{abstract}

Conclusion: These results suggested that the antigenome of a cytoplasmic RNA virus could be processed into functional miRNAs. Our findings provide new evidence supporting the hypothesis that cytoplasmic RNA viruses naturally encode miRNAs through cellular miRNA processing machinery.

Keywords: Hepatitis A virus, Antigenome, MicroRNA-like molecule, Picornavirus

\section{Background}

MicroRNAs (miRNAs) are small (approximately 22 nucleotide) regulatory non-coding RNAs that posttranscriptionally regulate gene expression by inhibiting the translation of mRNA transcripts or cleaving them [1-4]. MicroRNAs are encoded by cellular or viral genomes $[5,6]$

\footnotetext{
* Correspondence: huyunzhangym@126.com

'Yunnan Key Laboratory of Vaccine Research \& Development on Severe Infectious Diseases, Institute of Medical Biology, Chinese Academy of Medical Sciences \& Peking Union Medical College, Kunming 650118, China
} Full list of author information is available at the end of the article and play a vital role in numerous cellular processes, including cell metabolism, viral infection, and antiviral immune response [7-9].

Indeed, a large number of miRNAs have been discovered in numerous organisms [1]. As an effective and economic regulatory strategy of gene expression, miRNAs are employed by viruses to regulate the expression of their own genes, host genes, or both $[10,11]$. Most viral miRNAs have been identified by traditional cloning strategy from virus-infected cells [12-15], yet others have been identified following computational prediction and 
hybridization analysis [15-17]. The current release (v20.0) of the miRNA registry $[18,19]$ miRBase database lists 24,521 miRNAs, of which 493 viral miRNAs, indicating that diverse virus families encode miRNAs, including DNA and RNA viruses. It is noteworthy that the majority of known viral miRNAs are encoded by DNA viruses and only a few derived from RNA viruses. Indeed, DNA virusencoded miRNAs are generally accepted, while miRNAs from RNA viruses, especially those that replicate in the cytoplasm, are controversial $[10,11]$. The rationale is that viruses with DNA genomes that replicate in the nucleus have access to cellular miRNA processing machinery; on the contrary, RNA viruses replicate in the cytoplasm and therefore would not encode miRNAs due to inaccessible miRNA processing machinery $[10,11]$. Retroviruses are generally believed to have the ability to encode miRNAs since a DNA stage is included in their infectious cycle [20]. It has been speculated that RNA viruses do not generate miRNAs, in order to avoid the adverse effects caused by the miRNA processing machinery [8]. Therefore, naturally occurring miRNAs derived from RNA viruses have not been widely acknowledged.

To date, RNA virus-encoded miRNAs have been identified only in few retroviruses, including the human immunodeficiency virus (HIV) [21,22], bovine leukemia virus (BLV) $[20,23]$ and two cytoplasmic RNA viruses, namely the West Nile virus (WNV) and Dengue virus (DENV) $[24,25]$. Despite the theoretical barriers preventing cytoplasmic RNA viruses from encoding miRNAs, recent studies have confirmed that laboratory engineered RNA viruses, including the influenza virus, sindbis virus, and vesicular stomatitis virus (VSV), are capable of expressing miRNA-like small RNAs [26-30]. Furthermore, identification and validation of WNV and DENV derived miRNAs demonstrated that cytoplasmic RNA viruses indeed encode miRNAs through cellular miRNA processing machinery. Therefore, we hypothesized that the antigenome of a cytoplasmic RNA virus could be processed into miRNA-like small RNAs by the cellular miRNA processing machinery, similar to virus genomes. To test this hypothesis, we used a strategy that combined computational prediction and experimental validation with hepatitis A virus (HAV), a typical cytoplasmic RNA virus, searching for putative miRNA-like small RNAs. Although high-throughput sequencing has been widely used to characterize miRNA profiles and discover novel miRNAs in a variety of organisms, experimental screening of viral miRNAs by high-throughput sequencing of a large number of cDNA clones from infected cells is technically challenging, time consuming and likely incomplete. More importantly, viral gene expression displays highly constrained tissue-, time-, and replication state-specific patterns [17]. The above mentioned drawbacks could be efficiently overcome by a strategy combining computational prediction and experimental identification.

In the present study, HAV strain $\mathrm{H} 2$ was chosen as a model virus to investigate whether the antigenome of a cytoplasmic RNA virus can be processed into miRNAlike small RNAs, for the following reasons: first, the $\mathrm{H} 2$ strain of HAV is highly attenuated and does not cause disease in humans, which makes it an ideal model for studying HAV life cycle and virus-host interactions. In addition, HAV is a typical cytoplasmic RNA virus with approximately $7.5 \mathrm{~kb}$ genome and its antigenome is generated during viral replication. Finally, HAV has several unique biological characteristics that distinguish this virus from other members of the picornavirus family, including slow replication and persistent infection in most $\mathrm{HAV} /$ cell culture systems without a cytopathic effects [31-33]. Based on these HAV characteristics, we examined if its antigenome would encode miRNA-like small RNAs to regulate viral replication and virus-host interactions. Through computational prediction and experimental approaches, we demonstrated the generation and expression of a novel HAV antigenome-encoded miRNA in infected cells. This study provides new evidence supporting the hypothesis that a cytoplasmic RNA virus can encode functional miRNAs through cellular miRNA processing machinery. In addition, our findings provide a basis for further works assessing the roles of the HAV antigenome-encoded miRNA during virus infection and virus-host interactions. To our knowledge, this is the first study to identify and validate miRNAs on the antigenome of a cytoplasmic RNA virus.

\section{Results}

Putative pre-miRNA stem-loop structures and mature miRNAs in hepatitis $A$ virus antigenome

Computational prediction represents an effective strategy to identify novel miRNAs that can be further examined and validated by experimental approaches. Therefore, it is widely utilized to discover novel low abundance and temporal or tissue-specific miRNAs from various organisms [34]. In the HAV replication cycle, the antigenome is synthesized with a genome template [33]. RNA virus antigenomes distributed in the cytoplasm form various secondary structures and constitute potential pri/premiRNAs to generate miRNAs. In order to query whether HAV antigenome could be folded into putative premiRNA stem-loop structures, we analyzed its putative miRNA-encoding capacity. Using the VMir analyzer program $[16,35,36]$, 98 sequences located in HAV antigenome with potential stem-loop structures were found (Figure 1), suggesting the potential miRNA-encoding capacity of the HAV antigenome. Moreover, to identify conserved pre-miRNAs among different cell-adapted passages of HAV strain $\mathrm{H} 2$, all antigenomes from six $\mathrm{H} 2$ strain 


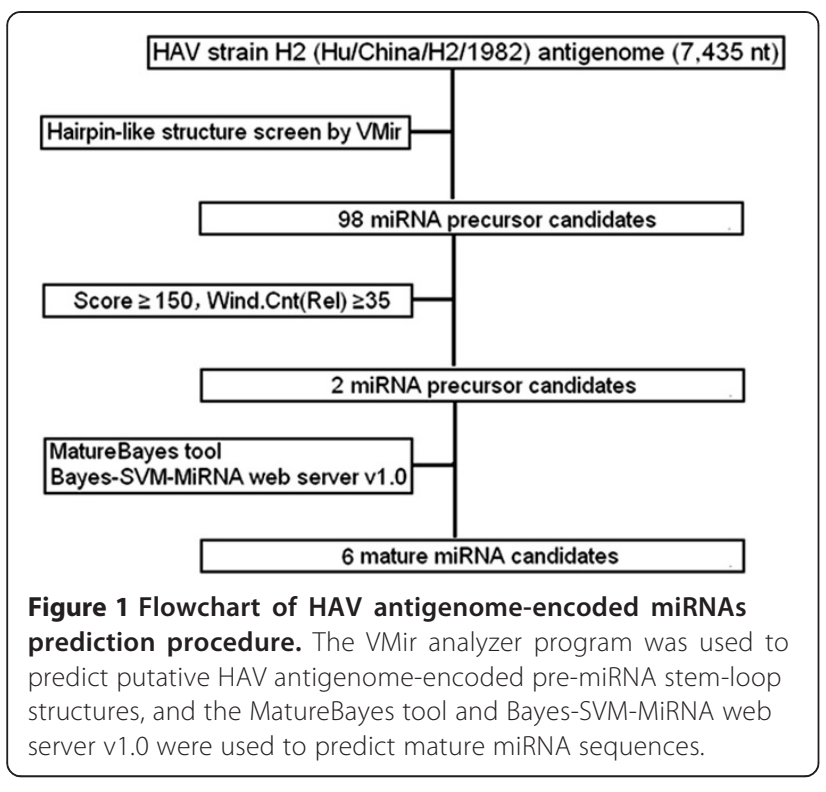

passages were screened using the VMir analyzer program. Two pre-miRNA candidates, MR50 and MR35, which were conserved among different HAVH2 cell-adapted passages (GenBank accession no. HAVH2K5: EF406358.1, HAVH2K10: EF406359.1, HAVH2K15: EF406360.1, HAVH2K20: EF406361.1, HAVH2K25: EF406362.1, and HAVH2K30: EF406363.1) with VMir score $\geq 150$ and window counts $\geq 35$, were selected (Figure 2A). More importantly, other pre-miRNA candidates with identical sequences and stem-loop structures as MR50 or MR35 were obtained in additional five antigenomes from HAV passages (Figure 2B), suggesting that MR50 and MR35 pre-miRNA sequences and structures were completely conserved among different HAV cell-adapted passages. Thus, MR50 and MR35 were considered putative premiRNA candidates, and their imperfect stem-loop secondary structures have typical characteristics of pre-miRNAs. VMir analyzer program prediction revealed that MR50 was derived from the cell-adapted HAVH2K5 passage (GenBank accession no. EF406358.1) and located on the antigenome (from 5894 to $5993 \mathrm{nt}, 100 \mathrm{nt}$ ), with a score of 177.3 and -23.6 minimal free energy. The other premiRNA, MR35, was located on the antigenome (from 4252 to $4352 \mathrm{nt}, 101 \mathrm{nt}$ ) with a score of 187.3 and -23.0 minimal free energy. Simultaneously, their secondary structures were predicted by RNAFold algorithms with typical imperfect stem-loop structures of pre-miRNAs (Figure 2B). Furthermore, considering about 22 nucleotides (nt) in length of the mature miRNAs spliced from pre-miRNAs, we predicted the potential mature miRNA candidates by the MatureBayes tool [37] (http://mirna.imbb.forth.gr/ MatureBayes.html) and Bayes-SVM-MiRNA web server v1.0 (http://wotan.wistar.upenn.edu/BayesSVMmiRNA find/) (Additional file 1). MatureBayes tool prediction revealed 4 putative mature miRNA candidates with $22 \mathrm{nt}$, namely MR50-1, -2 and MR35-1, -2 , and derived from 5p or 3p of two putative pre-miRNAs MR50 and MR35 (Table 1). Prediction results from Bayes-SVM-MiRNA web server v1.0 yielded 2 putative mature miRNA candidates with $21 \mathrm{nt}$. They were derived from $3 p$ and $5 p$ of the MR50 or MR35 stem-loop structure (Table 1) and termed as MR50-3, MR35-3. Overall, using computational approaches, we found that the antigenome of $\mathrm{HAVH} 2$ putatively encodes 2 pre-miRNAs and 6 mature miRNA candidates. These results provide evidence from bioinformatics perspective that HAV antigenome might encode miRNAs, and lay foundation for further experimental validation of the candidate miRNAs.

\section{A HAV antigenome-derived small RNA is generated and expressed in infected cells}

In order to ascertain whether the predicted miRNA candidates were indeed produced and expressed in HAV infected cells, stem-loop RT-PCR as well as PCR-based directed cloning and sequencing analyses were performed as previously described [38-40]. As shown in Figure 3A, a novel miRNA candidate, MR50-1, was successfully amplified specifically by stem-loop RT-PCR with a band of 63 bp in HAV-infected cells. In contrast, no corresponding band was observed in mock-infected cells. Considering the possibility that some predicted miRNAs might not be detected due to their low abundance, we performed a more sensitive qRT-PCR analysis. The results showed that MR50-1 was detected with a specific signal in HAV-infected cells; no signals for other miRNA candidates were detected (data not shown). More importantly, no specific signals for the predicted miRNA candidates except a cellular miR-154 (a well-annotated miRNA), were detected from RNA isolated from mockinfected cells. These results indicated that the miRNA candidate MR50-1 was indeed generated and expressed in HAV-infected cells. Furthermore, in order to determine the exact sequence of the amplified miRNA, a PCR-based directed cloning and sequencing analysis were performed. Interestingly, the amplified sequence of MR50-1 was completely consistent with the predicted MR50-1 (Figure 3B). Using the above methods, we obtained the exact sequence of MR50-1 and confirmed its expression during viral infection. MR50-1 represented a novel miRNA candidate and was named hav-miR-N1-3p. Although the 3p arm of the miRNA MR50 was detected, its 5p arm, including MR50-2 and MR50-3, could not be detected in our analysis. In addition, the sequencing results showed that the cellular miR-154 that served as a positive control, was also amplified with a band of $63 \mathrm{bp}$, suggesting that stem-loop RT-PCR is a highly specific and sensitive method for the detection of miRNA expression. To characterize specific temporal expression pattern of hav-miR-N1-3p throughout 


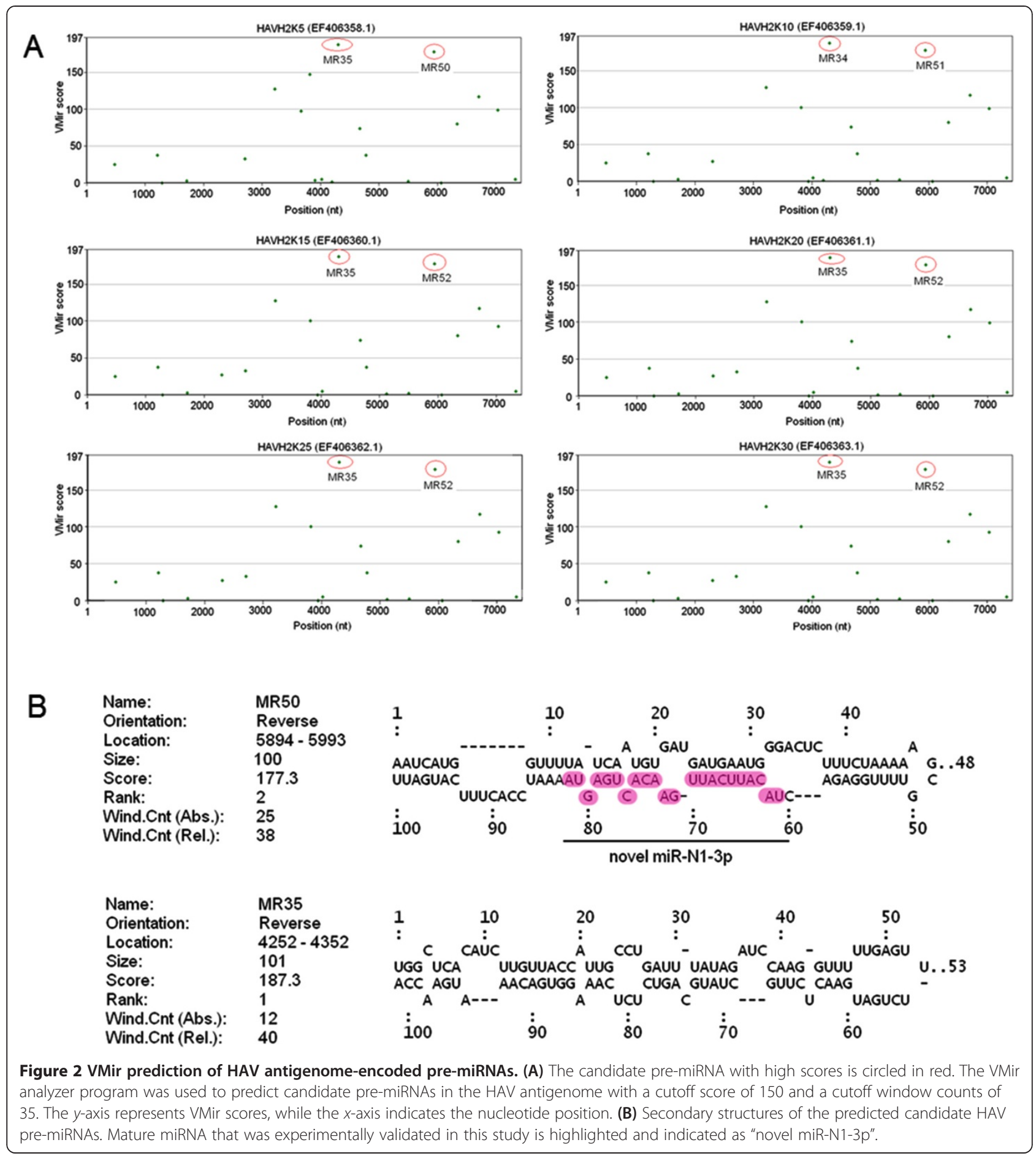

the infection, we performed a highly sensitive and specific qRT-PCR analysis. As shown in Figure 3C, the hav-miRN1-3p reached to a maximum plateau level at 4 hours post-infection, then decreased gradually and maintained a stable and low level during infection, whereas the value measured for cells non-infected remained at or close to backgrounds levels. The results suggested that the generation of hav-miR-N1-3p occurred in the initial stage of infection. As the infection progresses, hav-miR-N1-3p maintained a stable range with a low level. Notably, after we detected hav-miR-N1-3p in infected cells, we performed a northern blot assay to further confirm the presence of pre- and mature hav-miR-N1-3p and characterize its specific temporal expression pattern throughout the infection. Regrettably, we did not detect signals of the preand mature miRNA in all indicated time points (data not 
Table 1 Information of the predicted HAV antigenome-encoded miRNAs

\begin{tabular}{|c|c|c|c|c|c|}
\hline HAV miRNA $^{a}$ & miRNA sequence (5'-3') & Length (nt) & $3 p / 5 p$ & Position $^{\text {b }}$ (nt) & Prediction tool $^{c}$ \\
\hline MR50-1 & UACAUUCAUUGAACACUGAGUA & 22 & $3 p$ & 5912 to 5933 & MatureBayes \\
\hline MR50-2 & UAAAAAGCGUUUUGGAGACUAC & 22 & $5 p$ & 5931 to 5952 & MatureBayes \\
\hline MR50-3 & GAUGAUGAAUGGGACUCUUUC & 21 & $5 p$ & 5953 to 5973 & Bayes-SVM-MiRNA web server. \\
\hline MR35-1 & GAACUCUUGCUAUGCAGUCUCU & 22 & $3 p$ & 4272 to 4293 & MatureBayes \\
\hline MR35-2 & UGAUUUAUAGAUCCAAGGUUUU & 22 & $5 p$ & 4306 to 4327 & MatureBayes \\
\hline MR35-3 & CUAUGCAGUCUCUCAAAGGUG & 21 & $3 p$ & 4264 to 4284 & Bayes-SVM-MiRNA web server. \\
\hline
\end{tabular}

${ }^{a}$ The miRNAs (miR) derived from a single miRNA stem-loop precursor are indicated by a 5p (5' arm) or a 3p (3' arm) suffix.

${ }^{\mathrm{b}} \mathrm{Genomic}$ positions are provided based on the published HAV genome sequence (GenBank accession no. EF406358.1).

${ }^{\mathrm{C}}$ Prediction strategy of each mature miRNA sequence is shown in table.

shown). The major reason for this result is possible that low and inefficient viral replication lead to low miRNA copy number and low miRNA expression level. Therefore, low expression miRNA cannot be detected by northern blot owing to its limited detection sensitivity. Taken together, these results confirmed that the novel miRNA candidate hav-miR-N1-3p encoded by antigenome of HAV is indeed produced and expressed in HAV-infected cells.

\section{Depletion of Dicer decreases the expression of HAV antigenome-encoded hav-miR-N1-3p}

Dicer is well known as a key protein in the canonical cellular miRNA processing pathway, which is responsible for ultimately processing pre-miRNA into mature miRNA/miRNA* duplex [41]. It is well established that reduction of vital components of the miRNA processing pathway leads to an attenuation of miRNA steady-state levels [42]. Therefore, to ascertain whether hav-miR-N1$3 p$ is a product of the cellular Dicer processing pathway, a depletion of Dicer was carried out using siRNA-based RNAi approach followed by infection with HAV. Silencing efficiency of Dicer mRNA and protein were monitored by qRT-PCR and Western blot. As shown in Figure 4A, Dicer mRNA expression levels were reduced dramatically after transfection with Dicer-specific siRNAs, compared with negative control siRNA-treated cells. Furthermore, Dicer protein levels were reduced significantly in Dicer-specific siRNA group, compared with negative control siRNA-treated cells (Figure 4B). In addition, the expression difference in viral miRNA between Dicerknockdown cells and negative control cells was evaluated by qRT-PCR at 24 hours post-infection. As shown in Figure $4 \mathrm{C}$, a significant reduction of relative viral miRNA levels was observed in Dicer-knockdown cells, compared with negative control siRNA-transfected cells $(P<0.01)$. These results were in agreement with a report by Hussain et al. [24]. Additionally, we examined the effect of Dicer alteration on viral replication by qRT-PCR. Interestingly, alteration of Dicer expression did not affect the total amounts of viral RNAs (data not shown). These data demonstrated that depletion of Dicer decreased the expression of HAV antigenome-encoded miR-N1-3p. Collectively, these data suggested that havmiR-N1-3p is a product of the cellular Dicer processing pathway, rather than random degradation products of viral antigenomes. Notably, we also demonstrated that silencing of Drosha reduced hav-miR-N1-3p expression (Additional file 2), which suggested that hav-miR-N1-3p might be a Drosha-processing product.

\section{Transcription of HAV pre-miRNA in KMB17 and HEK293T cells from plasmid results in mature hav-miR-N1-3p production}

Because the viral hav-miR-N1-3p confirmed by cloning and sequencing may be a random degradation product from the viral antigenome, we carried out a plasmidderived miRNA expression analysis to exclude this possibility. In order to determine whether viral hav-miR-N1$3 p$ was derived from the MR50 precursor, the predicted HAV pre-miRNA MR50 was cloned into the mammalian expression plasmid pcDNA6.2-GW/EmGFP-miR to generate recombinant pcDNA6.2-GW/EmGFP-hav-premiRNA-50, which was transfected into KMB17 and HEK293T cells (Figure 5A). Total RNA isolated from cells transfected with the expression plasmid of viral havmiR-N1-3p or the negative control plasmid with scrambled sequences (Invitrogen) was subjected to a stem-loop RT-PCR analysis. Green fluorescent protein (EmGFP) with strong intensity was observed by fluorescence microscopy in both transfected cell groups (Figure 5B). Moreover, RT-PCR analysis revealed that viral hav-miRN1-3p was expressed with an apparent band of $63 \mathrm{bp}$ in KMB17 and HEK 293 T cells transfected with the havmiR-N1-3p expression plasmid pcDNA6.2-GW/EmGFPhav-pre-miRNA-50 (Figure 5C). In contrast, no bands were detected in cells transfected with the negative control plasmid. More importantly, sequence analysis of the PCR product indicated that the PCR amplicon sequence was completely consistent with viral hav-miR-N1-3p (data not shown). Furthermore, in order to determine whether viral hav-miR-N1-3p expressed by pcDNA6.2GW/EmGFP-hav-pre-miRNA-50 was generated from 

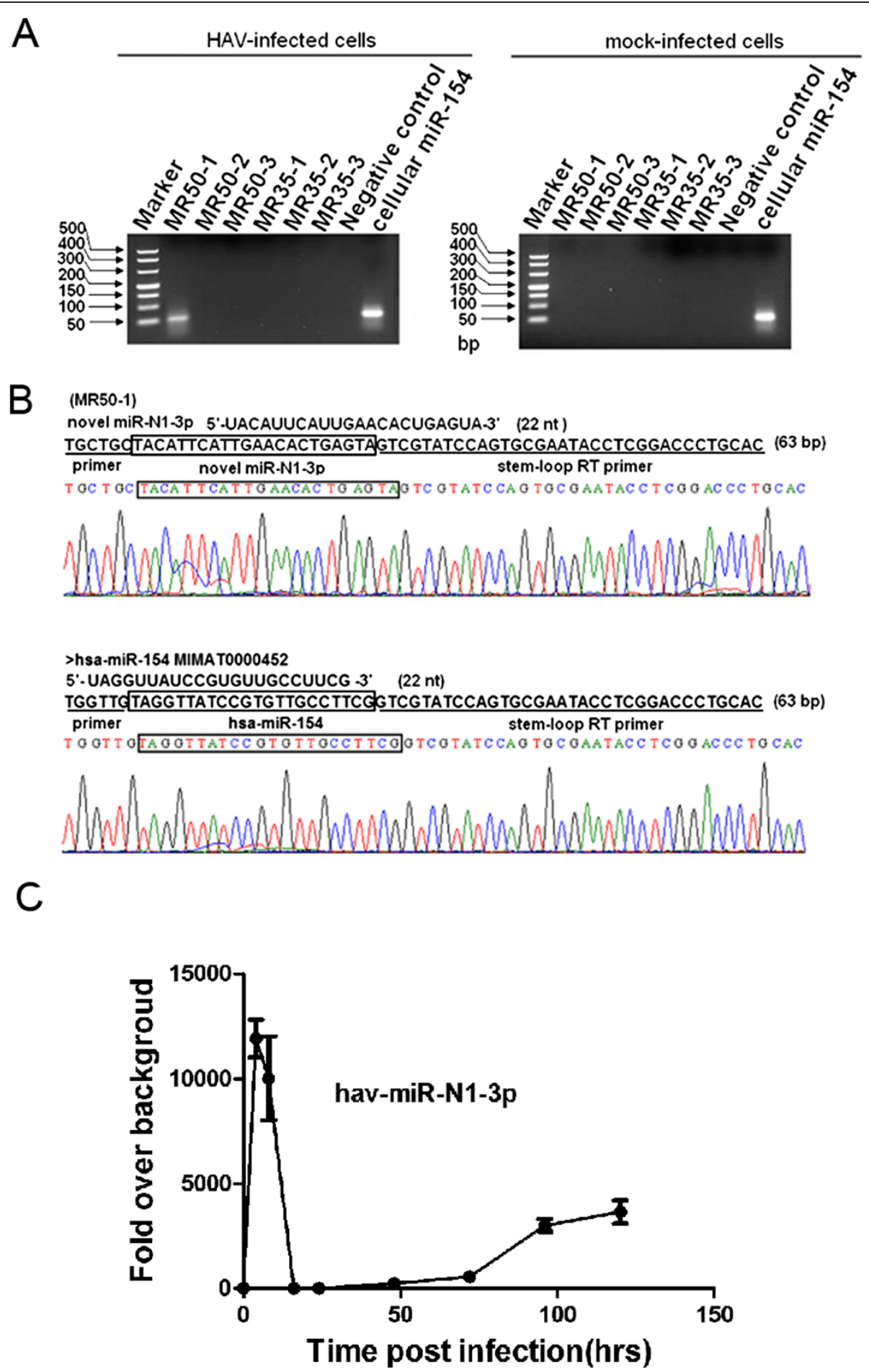

Figure 3 Cloning and expression validation of the predicted miRNAs in HAV-infected and mock-infected cells. (A) A HAV antigenome-encoded miRNA was detected in the HAV-infected cells. 4\% agarose gel electrophoresis analysis showed stem-loop RT-PCR products with approximately 63 bp specific bands. Cellular miR-154 was used as a positive control when performing agarose gel electrophoresis. (B) Sequencing results for the novel HAV miRNA and primer sequences are underlined in the sequencing maps. (C) Time course analysis of hav-miR-N1-3p in KMB17 cells. KMB17 cells were infected with HAV at a MOI of 0.5 TCID 50 cell. Total RNA was extracted at 0, 4, 8, 12, 24, 48, 72,96 and 120 hpi. and measured by qRT-PCR to quantify the expression of hav-miR-N1-3p during infection. All values are presented as changes in expression relative to uninfected cells after normalization to values of snU6 RNA. 


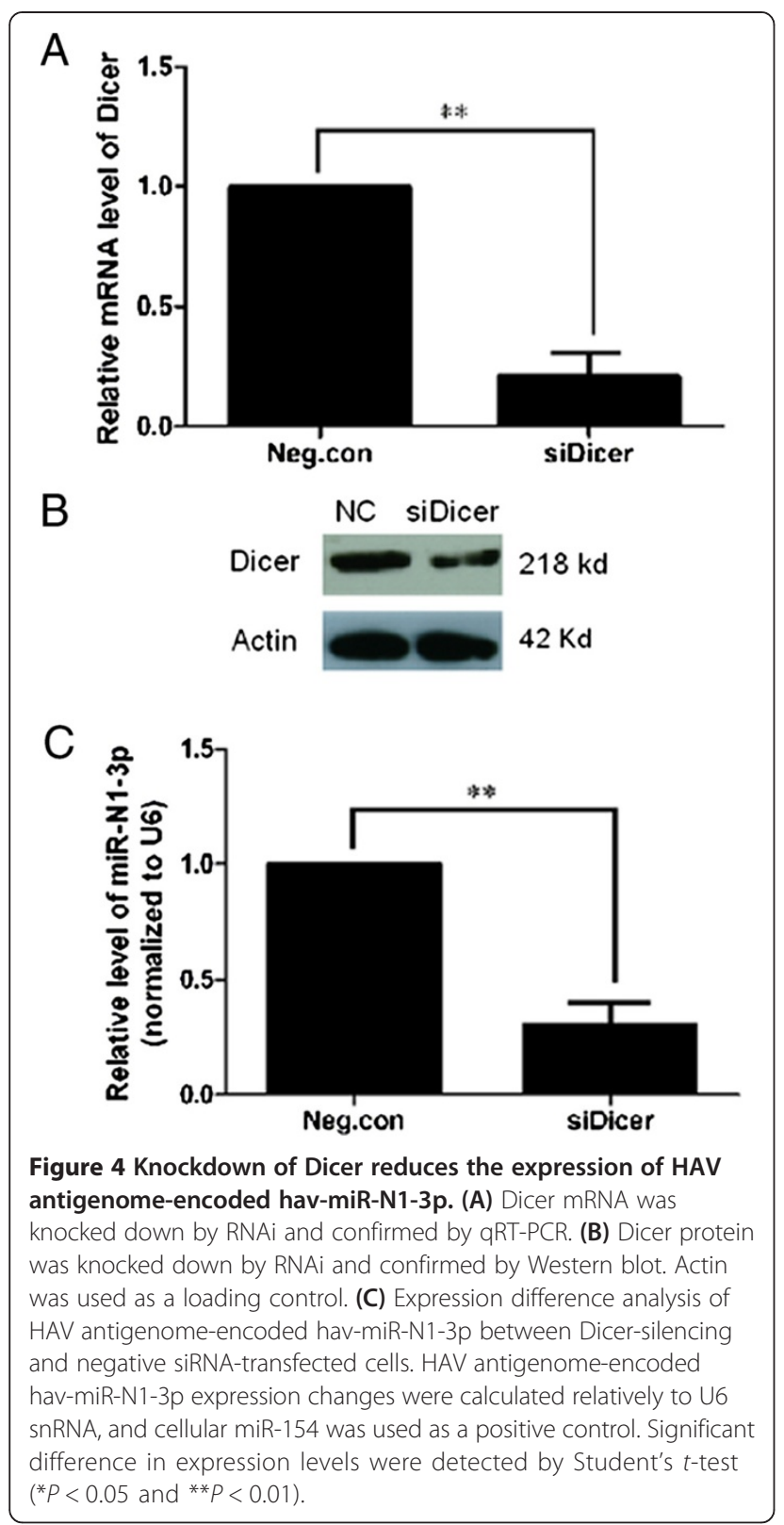

the predicted MR50 precursor by the Dicer processing pathway, we performed a silencing analysis of Dicer using RNAi approach in KMB17 and HEK293T cells. Knockdown of Dicer was monitored and confirmed by qRTPCR and Western blot (data not shown). Dicer-deficient and Dicer-non-deficient KMB17 and HEK293T cells were transfected with pcDNA6.2-GW/EmGFP-hav-pre-miRNA50, and qRT-PCR analysis was carried out to measure the relative levels of viral hav-miR-N1-3p. As shown in Figure 5D, a dramatic reduction in relative viral hav-miRN1-3p levels was found in Dicer-deficient cells, compared with Dicer-non-deficient cells $(P<0.01)$. Taken together, these data indicated that viral hav-miR-N1-3p is processed from the corresponding MR50 precursor by the Dicer processing pathway. Notably, when Dicer was knocked down by specific siRNAs, viral hav-miR-N1-3p and cellular miR-154 were all reduced significantly, compared with Dicer-non-deficient KMB17 or HEK293T cells (Figure 5D). These findings suggested that viral hav-miR-N1-3p expressed by the plasmid pcDNA6.2-GW/EmGFP-havpre-miRNA-50 was produced in a similar way to cellular miR-154. Furthermore, these results indicated that viral hav-miR-N1-3p is indeed derived from the splicing of the predicted MR50 precursor by the cellular miRNA processing pathway rather than the random degradation products of viral antigenome RNAs.

\section{HAV antigenome-encoded hav-miR-N1-3p is biologically functional and mediates post-transcriptional gene silencing (PTGS)}

One of the known biological characteristics of genuine miRNAs is that they can post-transcriptionally silence gene expression [6,24] namely PTGS. Therefore, in order to determine whether viral hav-miR-N1-3p is functionally active, a dual-luciferase reporter assay using pmirGLOhav-miR-N1-3p-sensor or pmirGLO-hav-miR-N1-3p-sensor-mut plasmid was carried out in HEK293T and KMB17 cells (Figure 6A). First, we tested the silencing activity of exogenous viral miR-N1-3p on artificial target of viral miRN1-3p with synthesized viral miRNA mimics in HEK293T cells. As shown in Figure 6B, relative luciferase activity was significantly reduced when co-transfected with hav-miRN1-3p miRNA mimics and pmirGLO-hav-miR-N1-3psensor plasmid, reaching up to $85.70 \pm 10.21 \%$ (Figure 6B; $P<0.01)$ after silencing compared to the negative control (mutated sensor plasmid). In addition, a lower silencing effect for cellular miR-154 $(96.40 \pm 4.46 \%)$ was observed (Figure 6B; $P<0.01$ ). These data indicated that synthesized viral hav-miR-N1-3p mimics is able to silence the expression of the luciferase gene with inserted artificial target of viral hav-miR-N1-3p and induced PTGS. Furthermore, in order to determine whether HAV naturally derived miR-N1-3p is able to silence the luciferase gene with inserted or mutated artificial target of viral hav-miRN1-3p, we assessed its silencing on sensor and sensor-mut plasmid in HAV-infected and mock-infected KMB17 cells. As shown in Figure 6C, a dramatic decrease in relative luciferase was observed with the sensor plasmid, compared to the negative control (mutated sensor plasmid), in HAVinfected cells. Silencing efficiency of viral hav-miR-N1-3p on its artificial target reached $43.22 \pm 11.04 \%$ (Figure $6 \mathrm{C}$; $P<0.05)$. However, no obvious difference for sensor and sensor-mut negative controls was observed in mockinfected cells (Figure 6C). These data suggested that hav-miR-N1-3p is capable of silencing the expression of the luciferase gene with inserted artificial targets of viral hav-miR-N1-3p, inducing PTGS. Overall, these results 
A

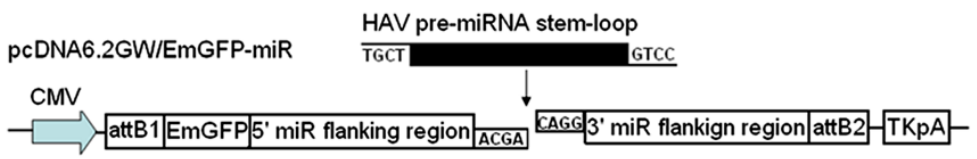

B

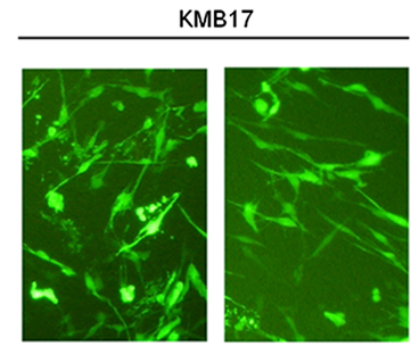

hav-miR-N1-3p hav-miR-N1-3p neg.
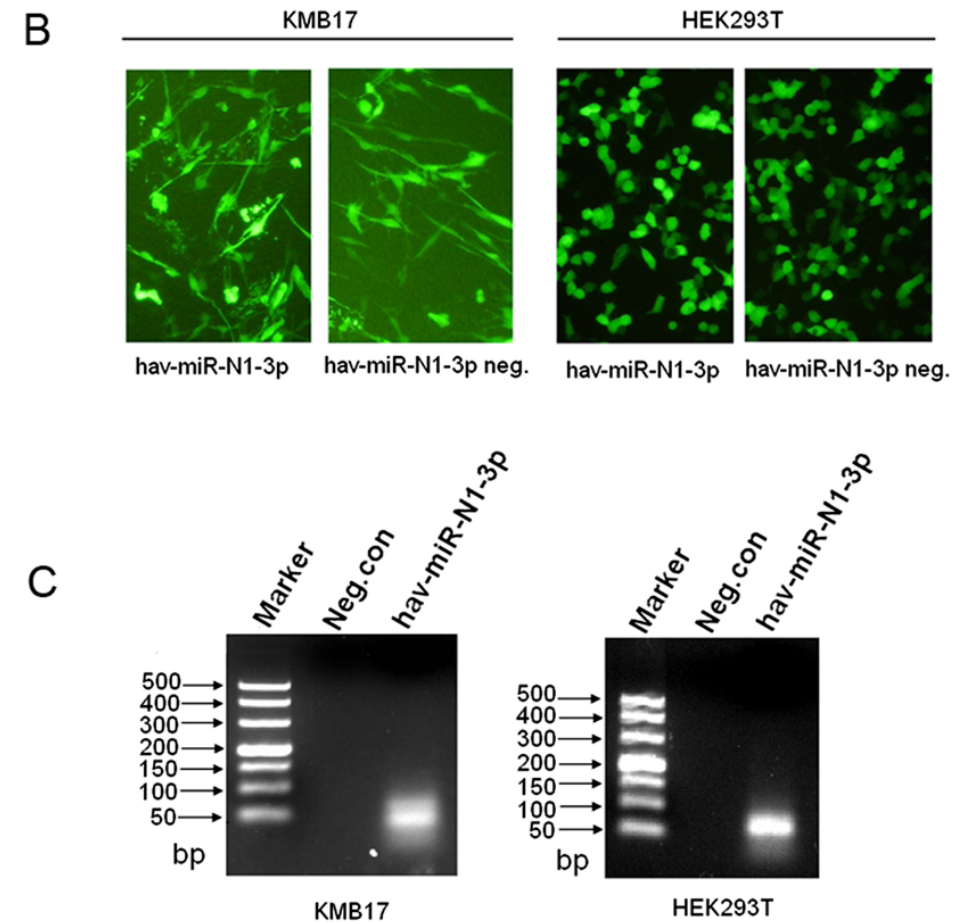

D

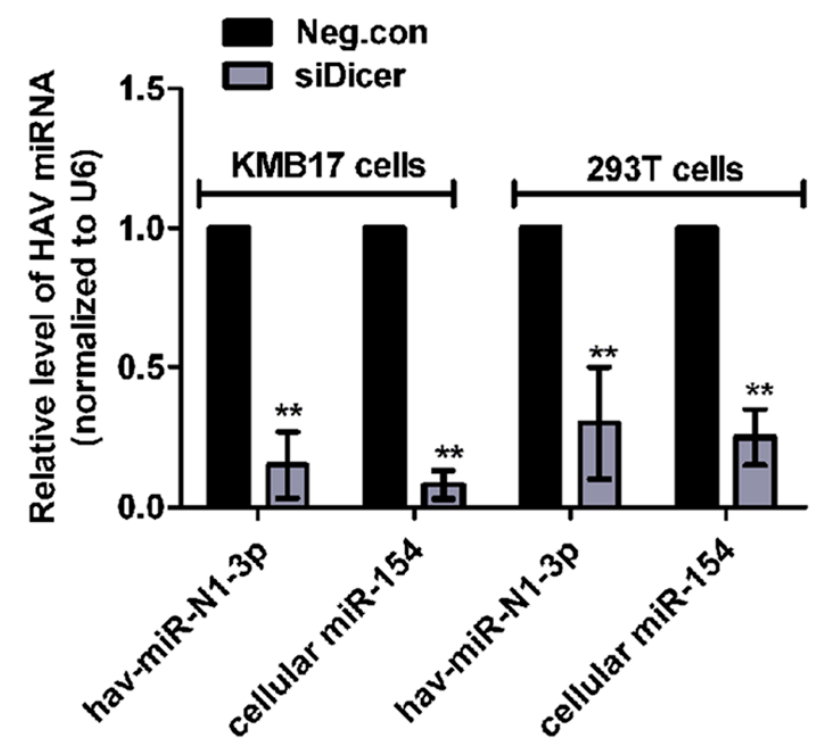

Figure $\mathbf{5}$ (See legend on next page.) 
(See figure on previous page.)

Figure 5 Detection of hav-miR-N1-3p from plasmid-expressed precursor miRNA (pre-miRNA). (A) Construction of miRNA expression plasmid. Each pre-miRNA sequence was cloned into a pcDNA6.2-GW/EmGFP-miR expression vector. The vector with scrambled sequences was used as a negative control. (B) KMB17 and HEK293T cells were transfected with miRNA expression plasmid, and strong green fluorescence was observed in both transfected cell lines $(100 \times$ ). (C) Detection of mature miRNA hav-miR-N1-3p expression. Small RNA was harvested at 24 hours post-transfection, and mature hav-miR-N1-3p was detected by stem-loop RT-PCR in both transfected cells. (D) Plasmid-expressed hav-miR-N1-3p was reduced in Dicer-deficient KMB17 and HEK293T cells compared with Dicer-non-deficient negative control cells. Significant difference in expression levels were detected by Student's $t$-test $\left({ }^{*} P<0.05\right.$ and $\left.{ }^{* *} P<0.01\right)$.

suggested that HAV antigenome-encoded hav-miR-N1-3p is a functionally active miRNA molecule.

\section{Discussion}

Although two novel miRNAs have been experimentally identified in WNV and DENV genomes, respectively $[24,25]$, the controversy remains as whether a virus with RNA genome that replicates in the cytoplasm can naturally encode functional miRNAs or miRNA-like small RNAs. The present study identified a novel miRNA-like small RNA generated from the antigenome of HAV strain $\mathrm{H} 2$ using computational prediction and experimental approaches. These findings provide new evidence for a cytoplasmic RNA virus encoding functional miRNAs.
In this study, bioinformatics analysis played a crucial role in the discovery of the novel viral miRNA. However, computational prediction does not necessarily implies that the predicted miRNAs are indeed generated and expressed in virus-infected cells. Thus, experimental validation of predicted miRNAs is required and needed. Several techniques are available for this validation including cloning, RT-PCR and deep sequencing. A PCR-based directed cloning and sequencing assay for the predicted miRNAs was performed in this study. The results indicated that the miRNA candidate MR50-1 was successfully amplified and its actual sequence was revealed by sequencing. Obviously, computational prediction followed by experimental validation constitutes an effective and fast strategy for discovery
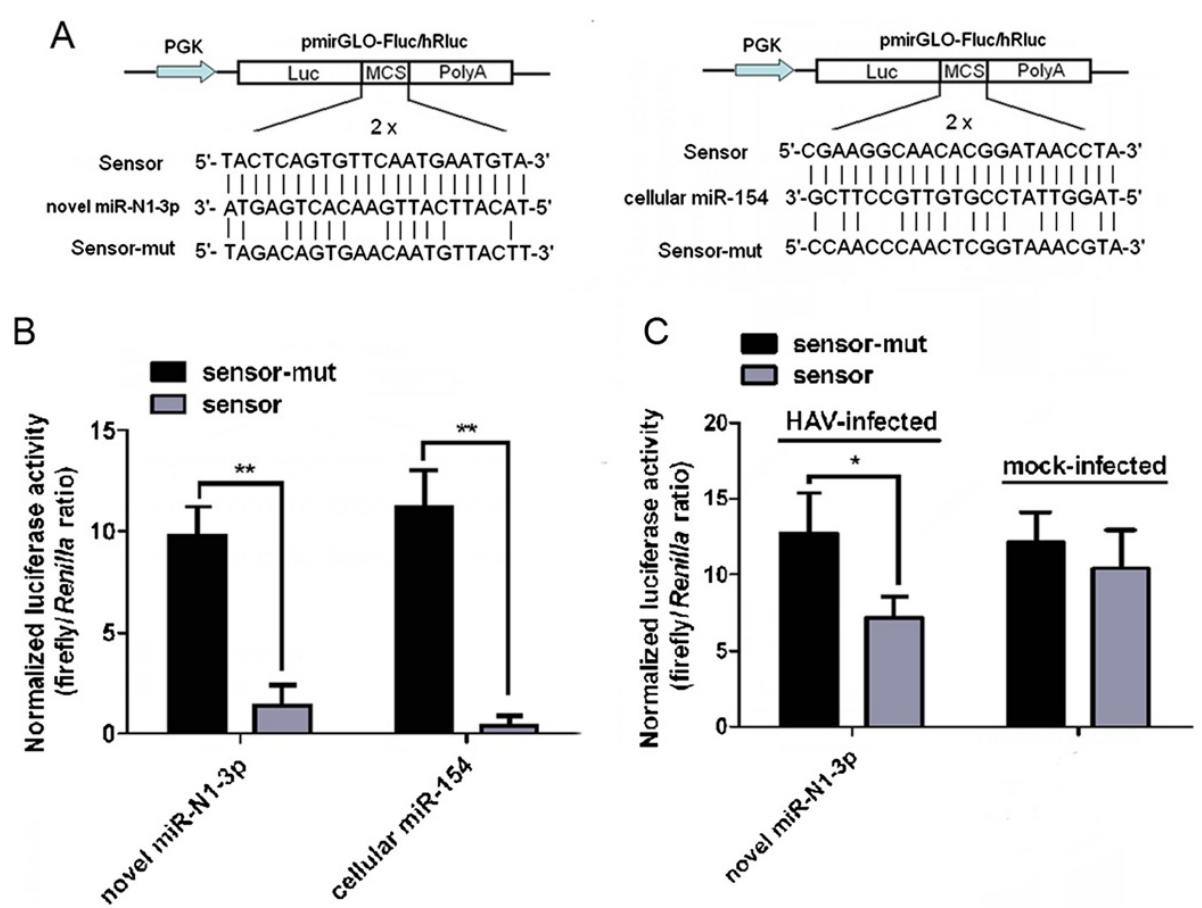

Figure 6 HAV antigenome-encoded hav-miR-N1-3p is a biologically functional miRNA. (A) Construction of sensor and sensor-mut plasmids. Sensor construct with two tandem repeats of artificial target sites perfectly complementary to the miRNA sequence were inserted into the 3' UTR of the luciferase gene in pmirGLO vector (sensor), and mutant construct with two tandem repeats of mutated nucleotides in the artificial target sites (sensor-mut). (B) Silencing activity of exogenous viral hav-miR-N1-3p in HEK293T cells transfected with viral miRNA mimics. (C) Silencing activity of endogenous viral hav-miR-N1-3p in HAV-infected and mock-infected cells. Luciferase activity was assessed 48 hours after transfection. A cellular miR-154 served as a positive control and the mutated plasmid was used as a negative control. For all treatments, relative luciferase activity was expressed as ratio of firefly to Renilla luciferase activity. Error bars indicate standard deviation obtained in three replicates, and significant differences are indicated with *at $P<0.05$ and ${ }^{*}$ at $P<0.01$. 
and identification of novel and rare, time-, and tissuespecific miRNAs. Several studies have previously employed this strategy to identify a few miRNAs in numerous viruses [43-45]. Using the VMir analyzer program, the simian virus 40 (SV40), Merkel cell polyomavirus (MCV) and murine polyomavirus $(\mathrm{PyV})$ have been confirmed to encode one or more miRNAs [5,6], which suggested that VMir analyzer program is an effective tool for searching new viral miRNA-like small RNAs.

As a RNA virus, HAV presents numerous mutations over its genome and antigenome during cell culture adaption [46-49], suggesting that the viral genome is not exactly the same among different cell-adapted passages and various HAV strains. Thus, it is difficult to find miRNAs that are completely conserved among different viral strains due to genome mutations. However, it is possible that some miRNAs are completely conserved among diverse viral cell-adapted passages. In this study, a specific HAV strain $\mathrm{H} 2$ was selected as a model virus. Using the VMir software, two miRNA precursors, MR50 and MR35, were found and shown to be completely conserved among different viral cell-adapted passages. These findings indicated that MR50 and MR35 stem-loops are always formed by the HAV strain $\mathrm{H} 2$ during infection. However, MR50 and MR35 are not conserved in other HAV strains. When other HAV strains were examined, other distinct pre-miRNA stem-loops were obtained, not MR50 and MR35. Theoretically, the HAV genome might form extensive RNA structures like antigenome, thus can be processed into miRNA-like small RNAs by the cellular miRNA machinery. Thus, we analyzed the genome of HAV with the VMir software, and obtained three premiRNAs, including MD5, MD61 and MD81, located in the viral genome coding region. These observations suggested that the RNA secondary structures of HAV strain $\mathrm{H} 2$ genome might be processed into miRNA-like small RNAs. It is noteworthy that the cellular miRNA machinery cannot distinguish viral genome from antigenome. However, the miRNA machinery can segregate stem-loop structures from non-stem-loop structures. This suggested that candidate pre-miRNA stem-loop structures, whether from viral genome or antigenome, might be processed into miRNA-like small RNAs. In the present study, we aimed to determine whether a cytoplasmic RNA virus antigenome can be processed into miRNA-like small RNAs. Thus, HAV genome-derived miRNAs are beyond the scope of the present work and will be further investigated in the future.

According to the criteria of novel miRNA annotation proposed by Ambros and Berezikov et al. [38,50], noncoding small RNAs are defined as genuine miRNAs that fulfill a combination of expression and biogenesis criteria. A novel HAV antigenome-encoded miRNA candidate hav-miR-N1-3p from this study was defined as bona fide miRNAs, fulfilling these annotation criteria. In addition, we identified HAV antigenome-encoded havmiR-N1-3p based on the miRNA biogenesis pathway and biologically silencing activity. Similar to previous results from Hussain et al. [24] for WNV encoded miRNA, silencing of Dicer led to a significant decline in hav-miR-N1-3p levels. Further, we noted that knockdown of Drosha reduced hav-miR-N1 expression. These findings further suggested that a cytoplasmic RNA virus could utilize the cellular miRNA processing machinery to produce their own miRNAs. Moreover, the biologically functional activity of the viral miRNA candidate was examined with robust silencing activity. This provides forceful evidence to support the conclusion that the viral miRNA candidate hav-miR-N1-3p was considered genuine miRNA. Overall, the predicted pre-miRNAs can be folded into typical stem-loop structures, and the mature sequence of $22 \mathrm{nt}$ detected in HAV-infected cells. Interestingly, the mature miRNA was derived from the splicing of the predicted pre-miRNA, and knockdown of Dicer and Drosha reduced hav-miR-N1-3p expression. Most importantly, hav-miR-N1-3p silenced luciferase gene expression, both exogenously and endogenously, suggesting the significant functional activity of hav-miRN1-3p. These results strongly indicated that hav-miRN1-3p is a genuine miRNA encoded by HAV antigenome. Further investigations will be needed to determine the mechanisms by which HAV antigenome encodes miRNA-like small RNAs as well as the potential biological function of viral miRNA during infection and host-virus interactions. However, the preliminary prediction of hav-miR-N1-3p target genes in host and virus provided some clues for better understanding of the regulatory roles of viral miRNA on host-virus interactions. Indeed, HAV antigenome-encoded hav-miR-N1-3p was completely complementary to the corresponding region of the viral genome, which might lead to targeted cleavage of the viral genome so as to regulate viral replication. HAV displays idiographic interactions with host immune responses [51], which suppress MAVS-mediated signal transduction and block IFN- $\beta$ induction [52-55]. Thus, genes involved in molecular pathways that are heavily affected by HAV might be regulated by the viral miRNA. Results of cellular target prediction analysis showed that havmiR-N1-3p had a good sequence complementary with MAVS mRNA. This suggests that hav-miR-N1-3p might interact with the MAVS gene to regulate cellular antiviral pathways through modulation of MAVS gene expression. Without a doubt, more studies are needed to further describe the regulatory roles of viral miRNA.

In summary, we predicted two putative viral premiRNAs and six mature miRNAs derived from HAV antigenome. A novel HAV antigenome-encoded miRNA hav-miR-N1-3p was experimentally identified and 
validated by different and complementary approaches. As a next step, target gene identification for hav-miRN1-3p will be performed to reveal its potential regulation of viral genes, host genes or both, involved in virus-cell interaction and viral replication in infected cells. Overall, this study is the first to report generation and expression of antigenome derived miRNA in a cytoplasmic picornavirus (hepatitis A virus), and strongly supports the idea that the antigenome of a cytoplasmic RNA virus can naturally encode functional miRNA-like small RNAs through the cellular miRNA processing machinery. Although the exact function of viral miRNA has not yet been elucidated, this study will facilitate further works on its potential biological roles.

\section{Conclusion}

This study demonstrated that the antigenome of a cytoplasmic RNA virus, hepatitis A virus, could be processed into functional miRNAs in infected cells. Our findings provide new evidence for the hypothesis that a cytoplasmic RNA virus can naturally encode miRNAs through cellular miRNA processing machinery.

\section{Methods}

Cells, viruses, plasmids and reagents

Human lung diploid fibroblastic KMB17 cells (Institute of Medical Biology, CAMS, Kunming, China) were grown in Minimum Essential Medium (MEM) supplemented with $10 \%$ bovine serum (Minhai Biotech, Beijing, China) at $37^{\circ} \mathrm{C}$ in a humid environment containing 5\% $\mathrm{CO}_{2}$. HEK293T cells were purchased from Thermo Scientific (Cat no. HCL4517) and grown in Dulbecco's modified Eagle's medium (DMEM) (high glucose formulation, Gibco, Life Technologies, Grand Island, NY, USA) supplemented with $10 \%$ fetal calf serum (Gibco Life Technologies, Grand Island, NY, USA) at $37^{\circ} \mathrm{C}$ in a humid environment containing $5 \% \mathrm{CO}_{2}$. Human hepatitis $\mathrm{A}$ virus strain $\mathrm{H} 2\left(\lg 10^{7.6} \mathrm{TCID}_{50} / \mathrm{ml}\right)$, an attenuated vaccine strain (Institute of Medical Biology, Kunming, CAMS) was prepared in KMB17 cells [56].

The eukaryotic expression plasmid pcDNA6.2-GW/ EmGFP-hav-pre-miRNA-50 obtained by inserting the entire viral pre-hav-miR-N1-3p sequence into pcDNA6.2GW/EmGFP-miR vector (Invitrogen, Carlsbad, CA, USA) was constructed via Gateway cloning using BLOCK-iT ${ }^{\text {mo }}$ Pol II miR RNAi Expression Vector Kits (Invitrogen, Carlsbad, CA, USA) according to the manufacturer's manual. The pmirGLO-hav-miRNA target expression plasmids wild-type (sensor) and mutant type (sensor-mut) were generated by inserting two tandem repeats of the antisense sequence of viral miRNA or cellular miR-154 (or mutated version) into 3' UTR of the luciferase gene of the pmirGLO vector (Promega, Madison, WI, USA), according to the manufacturer's protocol. All constructs generated were confirmed by sequencing using universal primers (BGI, Guangzhou, China).

Mouse monoclonal anti-Dicer1 antibody 5D12.2 (1:5000 dilution; mouse monoclonal; Millipore Corporation, Billerica, MA, USA), rabbit anti-actin polyclonal antibody (20536-1-Ap; 1:2000 dilution; rabbit polyclonal; Proteintech Group, Inc. Chicago, IL, USA), and appropriate HRP-conjugated anti-mouse and anti-rabbit secondary antibodies (1:10,000 dilution; Proteintech Group, lnc. Chicago, IL, USA) were used for immunoblotting.

\section{Bioinformatics prediction of the miRNAs}

A flowchart describing the computational prediction of putative miRNAs is shown in Figure 1. Briefly, the viral antigenome was scanned for miRNA precursors (premiRNA) stem-loop structures using VMir, a computational analyzer program $[16,35,36]$ for prediction of putative pre-miRNAs. Six complete antigenome sequences of different cell-adapted passaged HAV strain H2 (GenBank accession no. EF406358.1, EF406359.1, EF406360.1, EF406361.1, EF406362.1, EF406363.1) were used [56]. VMir predictions were carried out using default parameters. The putative pre-miRNAs that fulfilled filter parameters with VMir score $\geq 150$ and window counts $\geq 35$ were selected for further assessment. Subsequently, mature miRNA sequences from pre-miNRA stem-loops were predicted (Additional file 1). In order to extend the prediction coverage of the mature miRNAs, we performed two strategies: the MatureBayes tool [37] (http://mirna.imbb.forth.gr/MatureBayes.html) and BayesSVM-MiRNA web server v1.0 (http://wotan.wistar.upenn. edu/BayesSVMmiRNAfind/). Default conditions were followed for the MatureBayes tool. Folding energy was set at $-15 \mathrm{kcal} / \mathrm{mol}$ when using Bayes-SVM-MiRNA web server v1.0; other filter parameters were set to default values.

\section{Stem-loop RT-PCR analysis and PCR-based directed cloning of the miRNAs}

KMB17 cells were infected at a multiplicity of infection (MOI) of $1.050 \%$ tissue culture infective doses $\left(\mathrm{TCID}_{50}\right)$ /cell of HAV strain H2. Mock-infected cells was used as negative control. At 24 hours post-infection, total RNA was extracted with the Trizol reagent (Invitrogen China Ltd., Shanghai, China) according to manufacturer's protocol. A highly sensitive and specific stem-loop RTPCR was used to detect the expression of the candidate miRNAs as described previously [39,57], with minor modifications. Briefly, first strand cDNA of miRNAs were synthesized using stem-loop RT primers (Additional file 3) and Reverse Transcription System (Cat. no. A5001; Promega, Madison, WI, USA), following the manufacturer's instructions. Then, miRNA cDNAs were amplified by $\mathrm{PCR}$ in a mixture including rTaq DNA polymerase 
(TaKaRa, Dalian, China). The reaction mixture was subjected to $94^{\circ} \mathrm{C}$ for $5 \mathrm{~min}$, followed by 40 cycles of denaturation at $94^{\circ} \mathrm{C}$ for $15 \mathrm{sec}$, annealing at $56^{\circ} \mathrm{C}$ for $15 \mathrm{sec}$, and extension at $72^{\circ} \mathrm{C}$ for $30 \mathrm{sec}$. A cellular miR-154 was used as a positive control for miRNA size when products were separated by agarose gel electrophoresis. In addition, to determine the specificity of qPCR products, agarose gel electrophoresis analysis and T-A cloning strategy were conducted. The PCR products were analyzed on $4 \%$ agarose gel and purified PCR products were subcloned into the pGEM-T vector (Promega, Madison, WI, USA) and sequenced to verify the exact miRNA sequences. KMB17 cells were infected at MOI of $0.5 \mathrm{TCID}_{50} /$ cell of $\mathrm{HAV}$. Cells infected at various time points $0,4,8,12,24,48,72$, 96, 120 hours were analyzed for time course expression of miRNA. Stem-loop qRT-PCR was performed to quantify miRNA levels using Reverse Trancription System (Cat. no. A5001; Promega, Madison, WI, USA) and GoTaq qPCR kit (Cat. no. A6001; Promega, Madison, WI, USA). Cellular U6 snRNA was as an endogenous control. Relative expression levels were calculated using the $2^{-\Delta \Delta C t}$ method for infected versus uninfected cells [58].

\section{RNA interference (RNAi) of the Dicer gene}

The siRNA duplexes against the Dicer gene were synthesized according to sequences reported by Moore, et al. [59] and Bennasser, et al. [60] (Additional file 4). In order to avoid off-target effects, siRNAs were designed for multiple targets of the target gene. All siRNAs used for knockdown of the target gene and scrambled siRNA (a negative control) were chemically synthesized with 2' OME modification by GenePharma (Shanghai, China). siRNAs were dissolved in $0.1 \%$ diethylpyrocarbonate (DEPC) treated water to a final concentration of $20 \mu \mathrm{M}$ and stored at $-80^{\circ} \mathrm{C}$. $\mathrm{KMB} 17$ cells were seeded in 6-well plates one day before transfection. The next day, when the cells reached approximately $50-70 \%$ confluence, 100 pmol siRNA against Dicer mRNA or non-specific negative control siRNA were transfected into KMB17 or HEK293T cells using Lipofectamine 2000 (Invitrogen China Ltd., Shanghai, China), according to the manufacturer's protocol. Seventy-two hours after transfection, siRNAs transfected cells were lysed with RIPA buffer (Pierce, Rockford, IL, USA) containing the protease inhibitor PMSF (Solarbio, Beijing, China). Total cell protein extracts were collected for Western blot analysis.

\section{Real-time quantitative RT-PCR}

The expression levels of viral miRNA and the Dicer gene were analyzed by real-time quantitative RT-PCR (qRT-PCR) with specific primers (Additional files 3 and 5) using the Reverse Trancription System (Cat. no. A5001; Promega, Madison, WI, USA) and GoTaq qPCR kit (Cat. no. A6001; Promega, Madison, WI, USA) according to the manufacturer's instructions. For viral miRNA, cellular U6 snRNA gene was determined by qRT-PCR in parallel as an internal standard control. Total RNA was analyzed on a CFX96 ${ }^{\text {TM }}$ Real-Time PCR system (Bio-Rad, CA, USA) using the following program: $94^{\circ} \mathrm{C}$ for $5 \mathrm{~min}$, followed by 40 cycles of denaturation at $94^{\circ} \mathrm{C}$ for $15 \mathrm{sec}$, annealing at $56^{\circ} \mathrm{C}$ for $15 \mathrm{sec}$, and extension at $72^{\circ} \mathrm{C}$ for $30 \mathrm{sec}$. Relative miRNA abundance was normalized against cellular U6 snRNA content and assessed by the $2^{-\Delta \Delta C t}$ method [58]. For the Dicer gene, cellular Glyceraldehyde 3-phosphate dehydrogenase $(G A P D H)$ mRNA was determined by qRT-PCR in parallel as an endogenous control. Total RNA was analyzed on a CFX96 ${ }^{\text {TM }}$ Real-Time PCR system (Bio-Rad, CA, USA) under standard conditions using the following program: $94^{\circ} \mathrm{C}$ for $5 \mathrm{~min}$, followed by 40 cycles of denaturation at $94^{\circ} \mathrm{C}$ for $15 \mathrm{sec}$, annealing at $42^{\circ} \mathrm{C}$ for $15 \mathrm{sec}$, and extension at $72^{\circ} \mathrm{C}$ for $30 \mathrm{sec}$. Relative abundance of target gene mRNA was normalized to cellular GAPDH mRNA content and assessed by the $2^{-\Delta \Delta C t}$ method [58]. Melting curve analysis was also carried out to determine qPCR product specificity. The $\mathrm{Ct}$ (cycle threshold) values were determined using default threshold settings. All qRTPCR assays were performed with three biological replicates and three technical replicates.

\section{Western blot analysis}

Total protein in cell extracts was quantitated by the BCA protein assay Kit (Pierce, Rockford, IL, USA) according to manufacturer's instructions. Thirty micrograms total protein were resolved on $8 \%$ SDS-PAGE gels and transferred onto PVDF membranes (Millipore, Billerica, MA, USA), followed by blocking with $5 \%$ non-fat milk at room temperature for 2 hours. Membranes were probed with specific primary antibody overnight at $4^{\circ} \mathrm{C}$, followed by incubation with appropriate (anti-mouse or anti-rabbit) HRP-conjugated secondary antibody at room temperature for 1 hour. Protein signals were visualized by ECL chemiluminescence using Immobilon Western HRP Substrate (Millipore Corporation, Billerica, MA, USA) according to the manufacturer's protocol.

\section{Luciferase reporter assay}

A dual luciferase reporter assay using pmirGLO-hav-miRN1-3p sensor and pmirGLO-hav-miR-N1-3p-sensormut was performed in HEK293T and KMB17 cells. Briefly, HEK293T cells were seeded at approximately $1 \times 10^{6}$ cells per well in a 24-well plate one day before transfection. The next day, $200 \mathrm{ng}$ pmirGLO-hav-miRN1-3p-sensor or pmirGLO-hav-miR-N1-3p-sensor-mut plasmid were co-transfected with 20 pmol chemically synthesized miRNA mimics (GenePharma, shanghai, China) (Additional file 6) into HEK293T cells with Lipofectamine 2000 (Invitrogen). A cellular miR-154 served as a positive 
control, and mutated pmirGLO-hav-miR-N1-3p-sensormut was used as a negative control. Additionally, KMB17 cells prior to infection with $\mathrm{HAV}\left(\mathrm{MOI}=10.0 \mathrm{TCID}_{50} / \mathrm{cell}\right)$ were seeded at approximately $1 \times 10^{6}$ cells per well in a 24well plate one day before transfection. The next day, 200 ng wild type and mutated reporter sensor plasmids were transfected into HAV-infected and mock-infected KMB17 cells. The firefly and Renilla luciferase activities were evaluated simultaneously 48 hours post-transfection using the Dual-Glo ${ }^{\mathrm{Ta}}$ Luciferase Assay System (Promega, Madison, WI, USA) according to the manufacturer's protocol. Relative luciferase activity was expressed as the ratio of firefly to Renilla luciferase activity. The transfections were performed independently, in triplicate.

\section{Statistical analysis}

Values from three independent experiments were analyzed by two-tailed Student's $t$-test. $P<0.05$ was considered statistically significant and $P<0.01$ highly statistically significant.

\section{Additional files}

Additional file 1: Table S1. Prediction of mature miRNAs derived from HAV antigenome by MatureBayes tool and Bayes-SVM-MiRNA web server v1.0.

Additional file 2: Figure S1. Knockdown of Drosha reduced hav-miR-N1-3p expression.

Additional file 3: Table S2. Primers for stem-loop (q) RT-PCR of miRNAs Oligonucleotide sequences for real-time quantitative PCR analysis.

Additional file 4: Table S3. Oligonucleotide sequences for RNA interference (RNAi). siRNA duplexes against the Dicer gene.

Additional file 5: Table S4. Primers for GRT-PCR of Dicer gene mRNA. Oligonucleotide sequences for real-time quantitative PCR analysis.

Additional file 6: Table S5. Synthesized viral miRNA mimics for the luciferase reporter assay.

\section{Abbreviations}

HAV: Hepatitis A virus; miRNA: MicroRNA; pri-miRNA: Primary miRNA; premiRNA: Precursor miRNA; mRNA: Messenger RNA; nt: Nucleotide; bp: Base pair; 3' UTR: 3' Untranslated region; WNV: West Nile virus; DENV: Dengue virus; qRT-PCR: Quantitative reverse transcriptase-polymerase chain reaction; PTGS: Post-transcriptional gene silencing.

\section{Competing interests}

The authors declare that they have no competing interests.

\section{Authors' contributions}

JDS and YZH designed the experiments; JDS, ZQD, BW, MNW, JZ performed the experiments; JDS, JS analyzed data; JDS wrote the manuscript; NZH and $\mathrm{HXW}$ provided important reagents and analysis tools; YZH provided overall supervision and financial support and edited the manuscript. All authors read and approved the final manuscript.

\section{Acknowledgments}

The authors thank Yue Wang, Liping Wang and Hongzhi Cai for technical assistance. This study was supported by grants from the National High Technology Research and Development Program (863 Program) of China (Grant No. 2012AA02A406), the Applied and Fundamental Research program of Yunnan Province (Grant No. 2013FA025), and the Innovation Team Project of Yunnan province of China "Provincial Innovation Team for Application Research on New Types of Vaccine Adjuvant, Institute of Medical Biology, Chinese Academy of Medical Sciences" (Grant No. 2011Cl140).

\section{Author details}

YYunnan Key Laboratory of Vaccine Research \& Development on Severe Infectious Diseases, Institute of Medical Biology, Chinese Academy of Medical Sciences \& Peking Union Medical College, Kunming 650118, China.

${ }^{2}$ Department of Life Science and Biotechnology, Kunming University, Kunming 650214, China.

Received: 9 March 2014 Accepted: 24 June 2014

Published: 1 July 2014

\section{References}

1. Almeida MI, Reis RM, Calin GA: MicroRNAhistory: discovery, recentapplications, and nextfrontiers. Mutat Res 2011, 717:1-8.

2. Brodersen $\mathrm{P}$, Voinnet $\mathrm{O}$ : Revisiting the principles of microRNA target recognition and mode of action. Nat Rev Mol Cell Biol 2009, 10:141-148.

3. Carthew RW, Sontheimer EJ: Origins and Mechanisms of miRNAs and siRNAs. Cell 2009, 136:642-655.

4. Kim VN, Han J, Siomi MC: Biogenesis of small RNAs in animals. Nat Rev Mol Cell Biol 2009, 10:126-139.

5. Sullivan CS, Sung CK, Pack CD, Grundhoff A, Lukacher AE, Benjamin TL, Ganem D: Murine Polyomavirus encodes a microRNA that cleaves early RNA transcripts but is not essential for experimental infection. Virology 2009, 387:157-167.

6. Seo GJ, Chen CJ, Sullivan CS: Merkel cell polyomavirus encodes a microRNA with the ability to autoregulate viral gene expression. Virology 2009, 383:183-187.

7. Walz N, Christalla T, Tessmer U, Grundhoff A: A global analysis of evolutionary conservation among known and predicted gammaherpesvirus microRNAs. J Virol 2010, 84:716-728.

8. Kincaid RP, Sullivan CS: Virus-encoded microRNAs: an overview and a look to the future. PLoS Pathog 2012, 8:1003018.

9. Sun W, Julie Li YS, Huang HD, Shyy JY, Chien S: microRNA: a master regulator of cellular processes for bioengineering systems. Annu Rev Biomed Eng 2010, 12:1-27.

10. Cullen BR: Viruses and microRNAs. Nat Genet 2006, 38(Suppl):S25-S30

11. Grundhoff A, Sullivan CS: Virus-encoded microRNAs. Virology 2011, 411:325-343.

12. Pfeffer S, Zavolan M, Grässer FA, Chien M, Russo JJ, Ju J, John B, Enright AJ, Marks D, Sander C, Tuschl T: Identification of virus-encoded microRNAs. Science 2004, 304:734-736.

13. Cai X, Lu S, Zhang Z, Gonzalez CM, Damania B, Cullen BR: Kaposi's sarcomaassociated herpesvirus expresses an array of viral microRNAs in latently infected cells. Proc Natl Acad Sci U S A 2005, 102:5570-5575.

14. Samols MA, Hu J, Skalsky RL, Renne R: Cloning and identification of a microRNA cluster within the latency-associated region of Kaposi's sarcoma-associated herpesvirus. J Virol 2005, 79:9301-9305.

15. Pfeffer $S$, Sewer A, Lagos-Quintana M, Sheridan R, Sander C, Grässer FA, van Dyk LF, Ho CK, Shuman S, Chien M, Russo JJ, Ju J, Randall G, Lindenbach BD, Rice CM, Simon V, Ho DD, Zavolan M, Tuschl T: Identification of microRNAs of the herpesvirus family. Nat Methods 2005, 2:269-276.

16. Sullivan CS, Grundhoff AT, Tevethia S, Pipas JM, Ganem D: SV40-encoded microRNAs regulate viral gene expression and reduce susceptibility to cytotoxic T cells. Nature 2005, 435:682-686.

17. Cui C, Griffiths A, Li G, Silva LM, Kramer MF, Gaasterland T, Wang XJ, Coen DM: Prediction and identification of herpes simplex virus 1-encoded microRNAs. J Virol 2006, 80:5499-5508.

18. Griffiths-Jones S: The microRNA Registry. Nucleic Acids Res 2004, 32:D109-D111.

19. Griffiths-Jones S, Grocock RJ, van Dongen S, Bateman A, Enright AJ: miRBase: microRNA sequences, targets and gene nomenclature. Nucleic Acids Res 2006, 34:D140-D144.

20. Kincaid RP, Burke JM, Sullivan CS: RNA virus microRNA that mimics a B-cell oncomiR. Proc Natl Acad Sci U S A 2012, 109:3077-3082.

21. Zhang Y, Fan M, Geng G, Liu B, Huang Z, Luo H, Zhou J, Guo X, Cai W Zhang H: A novel HIV-1-encoded microRNA enhances its viral replication by targeting the TATA box region. Retrovirology 2014, 11:23. 
22. Kaul D, Ahlawat A, Gupta SD: HIV-1 genome-encoded hiv1-mir-H1 impairs cellular responses to infection. Mol Cell Biochem 2009, 323:143-148.

23. Rosewick N, Momont M, Durkin K, Takeda H, Caiment F, Cleuter Y, Vernin C, Mortreux F, Wattel E, Burny A, Georges M, Van den Broeke A: Deep sequencing reveals abundant noncanonical retroviral microRNAs in B-cell leukemia/ lymphoma. Proc Natl Acad Sci U S A 2013, 110:2306-2311.

24. Hussain M, Torres S, Schnettler E, Funk A, Grundhoff A, Pijlman GP, Khromykh AA, Asgari S: West Nile virus encodes a microRNA-like small RNA in the $3^{\prime}$ untranslated region which up-regulates GATA4 mRNA and facilitates virus replication in mosquito cells. Nucleic Acids Res 2012, 40:2210-2223

25. Hussain M, Asgari S: MicroRNA-like viral small RNA from Dengue virus 2 autoregulates its replication in mosquito cells. Proc Natl Acad Sci U S A 2014, 111:2746-2751.

26. Rouha $\mathrm{H}$, Thurner $\mathrm{C}$, Mandl $\mathrm{CW}$ : Functional microRNA generated from a cytoplasmic RNA virus. Nucleic Acids Res 2010, 38:8328-8337.

27. Varble A, Chua MA, Perez JT, Manicassamy B, García-Sastre A, tenOever BR Engineered RNA viral synthesis of microRNAs. Proc Natl Acad Sci U S A 2010, 107:11519-11524.

28. Shapiro JS, Varble A, Pham AM, Tenoever BR: Noncanonical cytoplasmic processing of viral microRNAs. RNA 2010, 16:2068-2074.

29. Varble A, ten Oever BR: Implications of RNA virus-produced miRNAs. RNA Biol 2011, 8:190-194

30. Usme-Ciro JA, Campillo-Pedroza N, Almazán F, Gallego-Gomez JC: Cytoplasmic RNA viruses as potential vehicles for the delivery of therapeutic small RNAs. Virol J 2013, 10:185.

31. Binn LN, Lemon SM, Marchwicki RH, Redfield RR, Gates NL, Bancroft WH: Primary isolation and serial passage of hepatitis $A$ virus strains in primate cell cultures. J Clin Microbiol 1984, 20:28-33.

32. Frings W, Dotzauer A: Adaptation of primate cell-adapted hepatitis A virus strain HM175 to growth in guinea pig cells is independent of mutations in the 5' nontranslated region. J Gen Virol 2001, 82:597-602.

33. Provost PJ, Hilleman MR: Propagation of human hepatitis A virus in cell culture in vitro. Proc Soc Exp Biol Med 1979, 160:213-221.

34. Thirugnanasambantham K, Hairul-Islam VI, Saravanan S, Subasri S, Subastri A: Computational approach for identification of Anopheles gambiae miRNA involved in modulation of host immune response. Appl Biochem Biotechnol 2013, 170:281-291.

35. Grundhoff A, Sullivan CS, Ganem D: A combined computational and microarray-based approach identifies novel microRNAs encoded by human gamma-herpesviruses. RNA 2006, 12:733-750.

36. Grundhoff A, Sullivan CS: Identification of viral microRNAs. Methods Enzymol 2007, 427:3-23.

37. Gkirtzou K, Tsamardinos I, Tsakalides P, Poirazi P: MatureBayes: a probabilistic algorithm for identifying the mature miRNA within novel precursors. PLOS One 2010, 5:e11843

38. Berezikov E, Cuppen E, Plasterk RH: Approaches to microRNA discovery. Nat Genet 2006, 38(Suppl):S2-S7.

39. Chen C, Ridzon DA, Broomer AJ, Zhou Z, Lee DH, Nguyen JT, Barbisin M Xu NL, Mahuvakar VR, Andersen MR, Lao KQ, Livak KJ, Guegler KJ: Real-time quantification of microRNAs by stem-loop RT-PCR. Nucleic Acids Res 2005, 33:e179.

40. Varkonyi-Gasic E, Wu R, Wood M, Walton EF, Hellens RP: Protocol: a highly sensitive RT-PCR method for detection and quantification of microRNAs. Plant Methods 2007, 3:12.

41. Meister G, Tuschl T: Mechanisms of gene silencing by double-stranded RNA. Nature 2004, 431:343-349.

42. Chua JH, Armugam A, Jeyaseelan K: MicroRNAs: biogenesis, function and applications. Curr Opin Mol Ther 2009, 11:189-199.

43. Singh J, Singh CP, Bhavani A, Nagaraju J: Discovering microRNAs from Bombyx mori nucleopolyhedrosis virus. Virology 2010, 407:120-128.

44. Hussain M, Taft RJ, Asgari S: An insect virus-encoded microRNA regulates viral replication. J Virol 2008, 82:9164-9170.

45. Besecker MI, Harden ME, Li G, Wang XJ, Griffiths A: Discovery of herpes B virus-encoded microRNAs. J Virol 2009, 83:3413-3416.

46. Hu NZ, Hu YZ, Shi HJ, Liu GD, Qu S: Mutational characteristics in consecutive passage of rapidly replicating variants of hepatitis $A$ virus strain $\mathrm{H} 2$ during cell culture adaptation. World J Gastroenterol 2002, 8:872-878.

47. Emerson SU, Huang YK, McRill C, Lewis M, Purcell RH: Mutations in both the $2 \mathrm{~B}$ and $2 \mathrm{C}$ genes of hepatitis $\mathrm{A}$ virus are involved in adaptation to growth in cell culture. J Virol 1992, 66:650-654.
48. Day SP, Murphy P, Brown EA, Lemon SM: Mutations within the $5^{\prime}$ nontranslated region of hepatitis A virus RNA which enhance replication in BS-C-1 cells. J Virol 1992, 66:6533-6540.

49. Graff J, Kasang C, Normann A, Pfisterer-Hunt M, Feinstone SM, Flehmig B: Mutational events in consecutive passages of hepatitis $A$ virus strain GBM during cell culture adaptation. Virology 1994, 204:60-68.

50. Ambros V, Bartel B, Bartel DP, Burge CB, Carrington JC, Chen X, Dreyfuss G, Eddy SR, Griffiths-Jones S, Marshall M, Matzke M, Ruvkun G, Tuschl T: A uniform system for microRNA annotation. RNA 2003, 9:277-279.

51. Dotzauer A, Kraemer $L$ : Innate and adaptive immune responses against picornaviruses and their counteractions: an overview. World J Virol 2012, 1:91-107.

52. Brack K, Berk I, Magulski T, Lederer J, Dotzauer A, Vallbracht A: Hepatitis A virus inhibits cellular antiviral defense mechanisms induced by doublestranded RNA. J Virol 2002, 76:11920-11930.

53. Fensterl V, Grotheer D, Berk I, Schlemminger S, Vallbracht A, Dotzauer A: Hepatitis A virus suppresses RIG-I-mediated IRF-3 activation to block induction of beta interferon. J Virol 2005, 79:10968-10977.

54. Paulmann D, Magulski T, Schwarz R, Heitmann L, Flehmig B, Vallbracht A, Dotzauer A: Hepatitis A virus protein 2B suppresses beta interferon (IFN) gene transcription by interfering with IFN regulatory factor 3 activation. J Gen Virol 2008, 89:1593-1604.

55. Yang Y, Liang Y, Qu L, Chen Z, Yi M, Li K, Lemon SM: Disruption of innate immunity due to mitochondrial targeting of a picornaviral protease precursor. Proc Natl Acad Sci U S A 2007, 104:7253-7258.

56. Mao JS, Dong DX, Zhang HY, Chen NL, Zhang XY, Huang HY, Xie RY, Zhou TJ, Wan ZJ, Wang YZ, Hu ZH, Cao YY, Liand HM, Chu CM: Primary study of attenuated live hepatitis A vaccine ( $\mathrm{H} 2$ strain) in humans. J Infect Dis 1989, 159:621-624.

57. Varkonyi-Gasic E, Hellens RP: Quantitative stem-loop RT-PCR for detection of microRNAs. Methods Mol Biol 2011, 744:145-157.

58. Livak KJ, Schmittgen TD: Analysis of relative gene expression data using real-time quantitative PCR and the 2(-Delta Delta $C(T))$ Method. Methods 2001, 25:402-408.

59. Moore HC, Johnston M, Nicol SM, Bourdon JC, Thompson AM, Hutvagner G, Fuller-Pace FV: An evolutionarily conserved, alternatively spliced, intron in the p68/DDX5 DEAD-box RNA helicase gene encodes a novel miRNA. RNA 2011, 17:555-562.

60. Bennasser $Y$, Chable-Bessia C, Triboulet R, Gibbings D, Gwizdek C, Dargemont C, Kremer EJ, Voinnet $O$, Benkirane M: Competition for XPO5 binding between Dicer mRNA, pre-miRNA and viral RNA regulates human Dicer levels. Nat Struct Mol Biol 2011, 18:323-327.

\section{doi:10.1186/1743-422X-11-121}

Cite this article as: Shi et al:: Identification and validation of a novel microRNA-like molecule derived from a cytoplasmic RNA virus antigenome by bioinformatics and experimental approaches. Virology Journal 2014 11:121.

\section{Submit your next manuscript to BioMed Central and take full advantage of:}

- Convenient online submission

- Thorough peer review

- No space constraints or color figure charges

- Immediate publication on acceptance

- Inclusion in PubMed, CAS, Scopus and Google Scholar

- Research which is freely available for redistribution 